\title{
Effects of Benthic Macrofaunal Bioturbation on the Preservation of Diatom Silica and Formation of Authigenic Products
}

DYLAN COLE ${ }^{1}$, NILS VOLKENBORN² ${ }^{2}$, AND JEFFREY W. KRAUSE ${ }^{1,3}$

${ }^{1}$ Dauphin Island Sea Lab, Dauphin Island, AL, 36528, USA (dcole@disl.edu, jkrause@disl.edu*)

${ }^{2}$ School of Marine and Atmospheric Sciences, Stony Brook University, Stony Brook, NY, 11794, USA

(nils.volkenborn@stonybrook.edu)

${ }^{3}$ University of South Alabama, Mobile, AL, 36688, USA

Bioturbating macroinfauna can be considered ecosystem engineers; however, the long-term impact of particle reworking and bioirrigation on elemental cycles is not well constrained. We analyzed sediment samples collected from $400 \mathrm{~m}^{2}$ experimental plots in the German Wadden Sea, where lugworms (Arenicola marina) have been permanently excluded from intertidal sandflats over the last 17 years by a $1-\mathrm{mm}$ polyethylene mesh buried at $10 \mathrm{~cm}$ depth in 2002 . The mesh prevented adult lugworms from establishing Jshaped burrows which typically are $20-30 \mathrm{~cm}$ deep, offering a unique opportunity to investigate the longterm consequences of bioturbation by adult lugworms on sediment silicon cycling. Samples were analyzed for both biogenic silica and acid-leachable silica - the latter being associated with early diagenetic products. Data from two exclusion and two non-exclusion (i.e. control) cores show enhancement in biogenic silica (34-fold increases) and acid-leachable silica (2-3-fold increases) in surface sediments $(0-5 \mathrm{~cm}$ depth) of exclusion plots. For both plot types, biogenic silica was highest at $10-20 \mathrm{~cm}$ and declined to minima at 30-40 $\mathrm{cm}$ with an increasing proportion of acid-leachable silica with depth, especially in exclusion plots. These data suggest that $A$. marina can significantly modify local silicon cycling by reducing sedimentary retention of biogenic silica and enhancing mobilization and benthic flux of dissolved silicate to the overlying water. 